\title{
Current State, Achievements, Challenges, Opportunities and Solutions of Vietnam's Higher Education in Global Integration
}

\author{
Dr. De Van Dinh \\ Dr. Loc Huu Pham \\ Ly Tu Trong College of Ho Chi Minh City, \\ 390 Hoang Van Thu St, Ward o4, \\ Tan Binh Dist, Ho Chi Minh City, Vietnam
}

DOI: https://doi.org/10.36941/jesr-2021-0027

\begin{abstract}
Over the last decades, Vietnam's higher education system has made remarkable achievements, and considerable contributions to the task of raising intellectual standards and human resources for the construction, protection, and development of the country. Besides the great achievements mentioned above, education in our country has still contained many weaknesses, shortcomings, and concerning issues. In particular, the quality of mass education, especially tertiary education is still in the lower ranking, the teaching methods are outdated as well as uncreative, conditions for higher education development are still inadequate; moreover, it is difficult for poor families, low-income families, and ethnic minorities to access higher education, besides, some negative phenomena in higher education are slowly solved. In order to resolve these problems, the purpose of this paper is to summarize the achievements and difficulties and to provide directions for building an education based on a solid theoretical foundation, focusing on researching the educational philosophy corresponding to requirements of the era and integration.
\end{abstract}

Keywords: higher education; the reality of education; education achievements; challenge and integration

\section{Introduction}

Educators and educational managers have analyzed and synthesized scientifically the drawbacks in the process of implementing innovations and proposed solutions so that the renovation of education and training has become successful. In the beginning, managers and scientists overall evaluated the situations, causes, and solutions about education and training in integration; had deep research into issues from awareness to implementation; explored the deployment from a flat world, studied barriers to adjusting the explicit implementation method, created harmony, cooperation and high consensus of the whole education system and society (Tran, 2015).

During the research process to find the best direction for education, it is obtained that there are positive changes from the macro-level of the whole system, the whole society to the micro one in the awareness of every citizen, every teacher, every learner about the necessities and actions to renew the education (Tran, 2014a).

First of all, we need to be deeply aware of the revolution and science of the educational renewal 
which is not dogmatic, local, and micro but is a "fundamental and comprehensive" innovation process at the macro ranking of the education system, leading to more effectively to a new level. These are the primary components that need to be researched objectively and explicitly both on a theoretical basis and in reality, being a foundation for educational renewal. These issues are very important, yet they have not been studied thoroughly and systematically, still existing some opposite opinions (Le, 2012).

However, the renovation performance must be carried out consistently from the highest to the most basic level synchronously, with an appropriate route as well as identified priorities, combining scientific research with experiment, practical theory with the efficient utilization, learning from experience and making amendments and supplements, so as not to allow serious mistakes that affect the whole system.

\section{Current Situations of Higher Education in Vietnam}

The deployment of human resource training must revolve around two fundamental issues in any country: training and employment. The fact shows that there is no common voice and tight relationship between the training and labour market. Therefore, the graduates find a hard time finding jobs because they do not have enough work skills to meet the labour market demand. According to the Ministry of Education and Training, in 2017, there were 215,3 thousand unemployment people in the group with a university or higher degree, accounting for 4,112\%; in 2018, there were 135,8 thousand people and approximately 2,57\% (Tran, 2015 and Tran, 2014a)

The main reason is the low quality of higher education, the universities are only interesting in developing quantity over quality, compare with the requirements of government's development, higher education is not considered as the leading national policy; the universities should keep the promise to make the learning education more effective and qualified as expected. Although learning education has fulfilled the task of knowledge transfer, the teaching of morality, career guidance, and learning attitudes have still been unqualified.

A random survey of 6o enterprises in service - industry sector about "Assessment of enterprises' satisfaction about the quality of student trained in the first five years after graduation" (based on the criteria: theoretical knowledge, practical skills, language proficiency, working style, and occupational competency) performs that only $5 \%$ rated as excellent, $15 \%$ good, $30 \%$ average and $40 \%$ fail. This result, not only reflects the weakness in higher education but also indirectly indicates a risk: in the condition that enterprises have been using automatical in human resource management, if Vietnamese employees are not actively improving their professional qualifications, practicing industrial manners, discipline, professionalism, they will lag behind other countries in the region (Tran, 2014a).

The role of education and training tends to human development to adapt to the urgent needs of the developing economy, therefore a high-quality education must-have. In training, it is a priority to reinforce personalities such as independence, sense of responsibility, and the ability to work in groups; relied on broad basic training which allows transferring between a variety of training forms; focused on social-occupational capacities and the labor market; adaptive ability and self-study (Boyatzis, 1982 and Boyatzi et al., 1995)

State management in education still exists many backward; for instance: education management structure is subsidized, not being untied; not making the most of the activeness and responsibility of basic units; having the inconsistent overlapping management; owning the incomplete subjective and unrealistic educational policies, lack of social agreement; besides, it contains the awkwardness and perceptions at a macro level, especially in terms of market economy and international integration; not responding the expectations of the country (Tran, 2014a and Tran, 2014b).

Training programs, contents, curriculum, and methods are still unsatisfactory, and outdated with a slow modernization, not yet associate with social life and occupational labor markets; not yet uphold creative thinking, the practical capacity of students. More importantly, the learners are not being at the center of the educational trajectory (Duc, 2014a). 


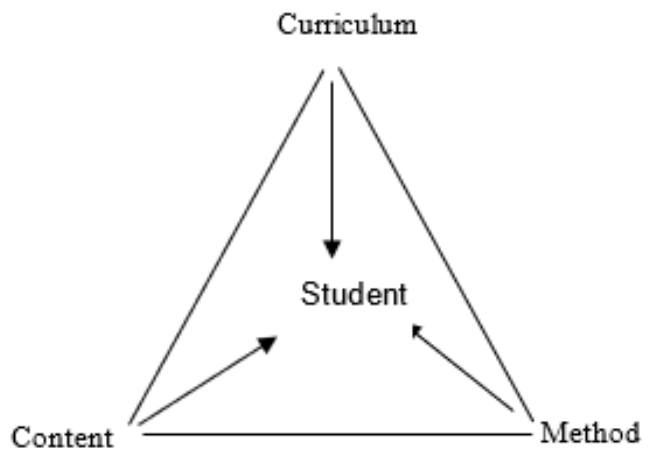

Figure 1: Relationship in teaching-learning

It is embarrassing and unclear to identify the principles to connect with foreign countries. The national education system is unsuitable for development, lacks synchronism, connectivity, and balance.

In both qualitative and quantitative terms, the quality of scientific research in higher education is still low and embraces various shortcomings, although the number of scientific staff, especially, doctors, associate professors, professors in our country is the highest in the region.

Critical thinking in education has not been properly grasped, slowly innovating, not fully and properly aware of educational socialization; failing to catch up with the core requirements of renovation with the objective of national development in the context of market economy and international integration. Furthermore, the University of Technology and Education, Technical Institute, or technical department of the university have not had full attention, and not had proper functions whereas they are mainly responsible for countless tasks (Tran, 2015)

There is a shortage of educational managers and teachers that are inadequate, in possession of the morality and competence weakness, mainly in the task of advising, forecasting, planning, working practices, financial management, foreign language skills, information technology, and ability to collect and process information.

The quality of higher education is declining, mostly moral education and lifestyle; ideological education, national history, creative thinking, practical skills, soft skills, lifestyles, morals, etc. The impact of the 4.o technology revolution on education is enormous, requiring changes in thinking, goals, curriculum, programs, methods, means of teaching organizations to connect the Industry 4.0; demanding lifelong learning, equipping new skills for each new profession; additionally, education in the Industry 4.0 requires creative, innovative skills, solving problem skill, critical thinking, human resource management, teamwork, etc.

It is a must to evaluate objectively the reality of education recently, the demands of the country in the new period, and the next research categories.

\section{Achievements, Opportunities, and Challenges of Vietnam's Higher Education}

In general, although higher education involves both the subjective and the objective, we can see that Vietnam's education accomplishes various commendable achievements that cannot be denied. Particularly, the learning needs for people are being satisfied, the strategic objectives of increasing intellectual standards, training human resources, fostering talents have accomplished some important results; the social policies on higher education has been better and more effective; the quality of higher education has made good initial changes both in quality and quantity; strengthen conditions to ensure possible developments for education. 


\subsection{Achievements of Vietnam's higher education}

The education and training have successfully recorded numerous remarkable achievements, greatly contributing to the building and defending of the country.

In particular, the system of schooling and educational scales are increasing more and more, learning needs are satisfying for the people. In other words, it is implementing a universal education to meet the needs of the people and improving the level of training and occupational skills for learners.

The strategic objectives of raising people's intellectual standards, training human resources, and fostering talents have received several important results, meeting the human resource requirements for the socio-economic development of the country. There is a gradual shift from the goal of knowledge enhancement to the development of quality and capacity for learners, which is evaluated to be close to the world standard.

The social policy on higher education has been made better and more effective. Educational socialization and international cooperation have been strengthened, achieving several significant effects. In shorts, there have been good initial changes in both quality and quantity; strengthening conditions to ensure the success of educational development (Paprock, 1996).

The management of education has led to a positive transformation. Such as the more rapidly educational staff has increased in terms of quantity the better training level has been in order to respond to the requirements in the modern era.

The facilities of the higher education system are gradually modernized, creating the most favorable teaching environment for lecturers and learners. Similarly, it is possible to approach teaching and assessment methods based on the competence of occupational skills, attitudes, and techniques that are able to apply effectively in real life. In training, personal improvement such as independence, sense of responsibility, and teamwork are put at the top of the priority list; and so tend to the advancement of social-occupational capacities which are related to the labour market; enhance adaptability and self-study (Tran, 2014a and Le, 2012).

Social equity in education has generated couples of considerate advances, especially for needy families, low-income families, ethnic minorities, rural workers, social policy beneficiaries, people with meritorious services, besides gender equality are guaranteed; facilitated for everyone to study at the right age and with their qualifications.

Regarding the worldview and philosophy of life, parents, educators, educational institutions, labour force, there has been a positive change at the macro ranking of the entire social system in management and administration, up to the micro-level in the awareness of every citizen, lecturer, and learner in the specific actions to innovate the education (Dooley et al., 2001).

A possible, dynamic, effective, and qualified education that adapts the country's development in the new era and is in line with the modern trends in the world.

\subsection{Opportunities and Challenges of Higher Education in Vietnam}

Among many nations of the world revolving around the fourth industrial revolution (or Industry 4.o)'s orbit, Vietnam also participates and is directly impacted by Industry 4.o. This creates opportunities while leaving the country with difficulties and challenges for higher education in particular and the industrialisation, modernisation process of the country in general.

Industry 4.0 can break the traditional workforce structure when robots replace the manual workforce in many industries and sectors of the economy. The impact of this revolution on the social workforce structure will change in different stages. 


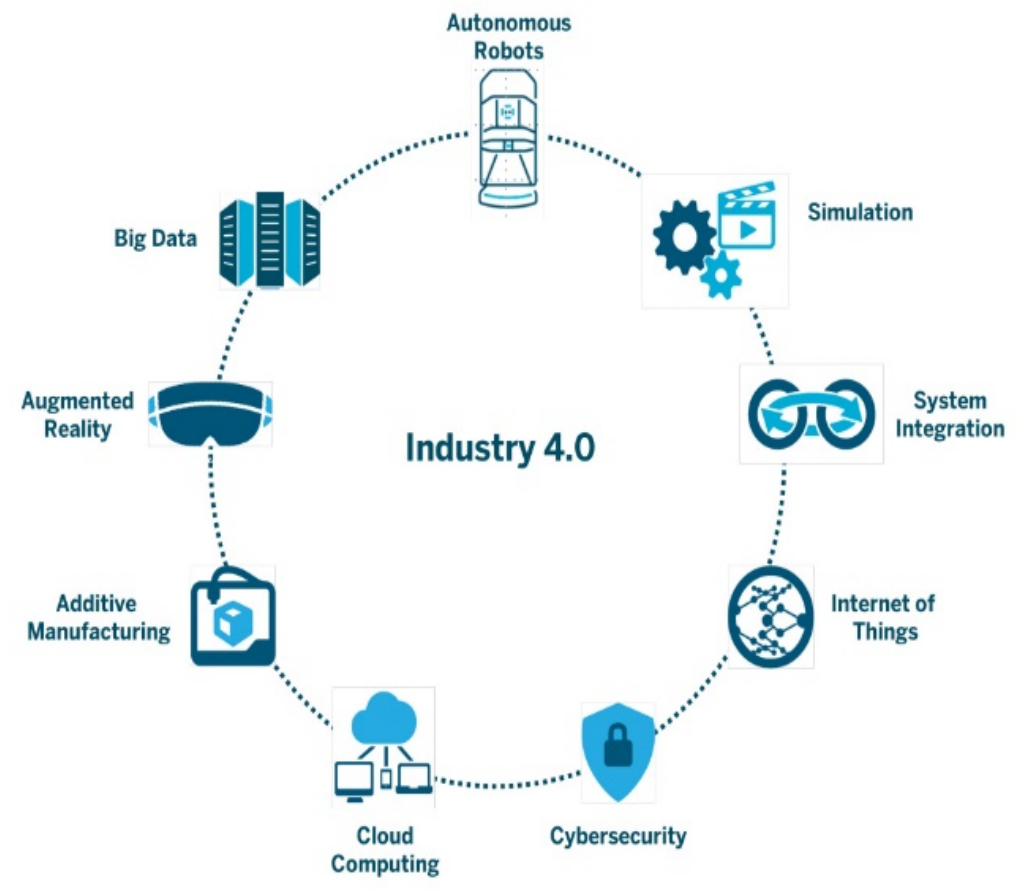

Figure 2: The cycle of Industry 4.o (Nguyen, 2003)

As the characteristics of Industry 4.o do not depend mainly on machines and equipment, but on human capacity, knowledge, and creativity, Vietnam, with a golden population structure, can avail the advantage of being one of the later participants of Industry 4.o.

Another opportunity and challenge for higher education in Vietnam are that while the world is entering the fourth industrial revolution, Vietnam is still mainly in the second phase (second industrial revolution), which also means manual assembly line, specifically: most small and medium enterprises in Vietnam (97\%) are currently using the technology of the 1980 , of which $52 \%$ are using outdated equipment, $38 \%$ are using the average equipment, only $10 \%$ is using the current device. The average cost of scientific and technological innovation of an enterprise is still too low, accounting for only $0.3 \%$ of total revenue (Nguyen, 2003).

The majority of Vietnamese workers are not well-trained, still lack theoretical knowledge and professional skills, i.e professional knowledge, foreign language ability to communicate, work and socialise. Calling this an opportunity to improve, this is also a challenge for higher education is entering the fourth industrial revolution, with an unskilled workforce, especially the limitations in high technology platforms, small and unsynchronised production (Boyatzis, 1982).

Changes in the online communication approaches are also opportunities and challenges for people in the digital age, especially the risk and danger of human health, financial security, cybersecurity, personal information also imposes higher requirements.

The center of higher education reform revolves around training high-quality human resources to meet the requirements of Industry 4.0.

Along with the rapid technology change, Industry 4.0 requires education to equip the learners with basic skills and knowledge, professional attributes, creativity, and adaptability to cope with challenges and changing job requirements to avoid the risk of being left behind and eliminated. With many new essential requirements in higher education, accepting the law of going forward means a 
possible elimination, so traditional education methods certainly do not fit in the category and hence, eliminated, as Education 4.o needs critical thinking, innovation, creativity, cultural knowledge, startup skills; intelligent agents using modern information; Mobile technology, Smartphone, cloud computing (Boyatzis et al., 1995).

In the context of the constantly changing world, while some countries have been finding the ultimate direction for education development and have found success, the education system in our country remains the same, still stuck in the backward situation. It is a fact in recent years, the development of higher education in our country has created an imbalance between the scope of majors and levels of education, forming fierce conflicts between effectiveness, quality, and scope of training.

Public opinion criticizes the outdated training and learning methods in higher education, the educational and training organisation model is still standardised in the form of academic learning with heavy theoretical studies, overlooking the practical studies.

Facts have shown that countries not only rely on the advantages of capital, technology, and natural resources but also have to research, study, manage and operate, seek solutions to find other advantages in innovation capacity and exploitation of human intelligence through education. Vietnam's higher education also follows the same path while eliminating the constraints obstructing higher education innovation.

On the other hand, in order to compensate for the limitations and shortages, Vietnam can avail a great advantage in human resources, which is the golden population generation, with the ability to quickly access and adapt to information technology and education. Education and training will be the key to unlock all the roles of science and technology. This is an opportunity but also a great challenge to higher education and training today.

\section{The Solutions for Higher Education in Vietnam}

To overcome these shortcomings, higher education needs to urgently implement the following: Successful research and apply innovation in educational philosophy, cognitive and critical thinking to meet the modern demands, renovating educational perspectives and goals, as these are the underlying issues, that if resolved, can initiate the process of renovating higher education. This innovation will be the premise of change, ranging from programs, training materials, textbooks, to teachers and how to teach. According to this new philosophy, the way of teaching and studying will change from studying to "remember" to studying to "understand" (Nguyen, 2003).

Equity in education should be well-implemented. Everyone has equal rights in education and educational obligations. The education system should be such that it must respect individuals, providing opportunities to develop their personalities, to create many paths and opportunities for learners to develop talents and become the talents of the country. Personality education is an important element that needs special attention; creativity, self-study, self-research, self-responsibility, and participation in group activities should be encouraged, promote high-order thinking ability for students; inspire real interest in scientific research, and cultivate the habit of self-reading, self-seeking information to enhance the understanding to apply academia in the flat world.

Basically and comprehensively changing the traditional assessment to competency-based assessment of both learning and creating content, evaluating learning outcomes and the application of learned skills and knowledge, practice into the actual experience environment ... (Tran, 2014a, and Nguyen and Dao, 2015).

The renovation of education management should be strengthened, especially the management of training quality; development of training curriculum having learning outcomes. The learning outcomes are written in the perspective of the learner, clearly stating what the learner will do after completing the module and the learning outcomes should be based on practice and the requirements of the society, meeting the diverse needs in types and quality.

Curriculum content and teaching methods should be strongly renovated towards regional and international integration. The content of the program is developed openly and has a life cycle of 3 to 5 
years; innovating learner-focused teaching methods.

The learner-focused teaching method is the teaching method in which the teacher no longer plays the leading role and the learner is no longer passive but becomes the center and subject of the teaching and learning activity. All are aimed at learners and for learners. Here, learners no longer passively receive the knowledge, they are no longer assigned to study just the knowledge of lectures, training materials, or textbooks, but learners are put in front of practical problems and situations (Rausch et al. 2001).

The power of the teacher is no longer based on the passivity and incompetence of the learner, but on the competence of the teacher, the teacher must be a guide, a mentor to the learner, rather than just playing the role of an instructor. Based on that, learners mobilise resources and experiences to analyse, synthesise, quantify, evaluate, explicitly solve problems.

All training methods are centered on the teaching-learning process. However, in the traditional training model, the teacher's role is appreciated. On the contrary, in the new training mode, the role of the learner is especially appreciated. The path to taking learners as the center is thoroughly understood from the program design stage, content, script, objectives development to the use of teaching methods, etc.

The learner-focused teaching method is to put learners into the right trajectory of education, following the rules of the educational process so that education can base and focus on the learners. With implementation capacity, passion, and personal conditions, learners will master their learning and research processes (Nguyen, 2014 and Doan, 2012).

Some say that a learner-focused teaching method has changed the traditional roles in the school. In this method, the role of the learner seems to overstep the responsibility of the teacher, creating a bad mentality for the learners and teachers. However, the absolute assertion of many leading pedagogical teachers about this is that the learner-focused teaching method or the positive teaching method of the learner is the return of the original position of the learner that has been accidentally missed for a long time.

In the context of Industry 4.0 and the formation of a digital economy, it is necessary to renovate the orientation and strategy for higher education training and development; development of higher education must be in association with the needs of socio-economic development; changing the educational process from essential academic knowledge to comprehensive development of learners' competence and quality, learning along with practicing, reasoning associated with practice and learning to experience.

\section{Vietnam's Higher Education on the Path of Integration and Collaboration}

International integration in higher education has been indirectly and directly impacting Vietnamese education, this is a problem that needs to be deeply and fully aware at the macro and micro level of higher education. Although our education is lagging behind many countries in the region and the world, our country's education is recognised as a service (by WTO and GAST); Based on this foundation, we have gradually opened up the education service market and promoted international cooperation (Tran, 2014a).

Higher education in Vietnam has access to changes in the function and mechanism of education development and of other fields from which research, comprehension, perception and approach to the world education are taking place with new trends with many important factors for the success of higher education as below:

Firstly, the trend of popularisation; it is suitable for all people in the world and serves the interests of all people in the world.

Secondly, the development of distance learning, online training; diversify methods and modes of education; Change the model and function of educational institutions.

Thirdly, regionalisation, globalisation, collaboration and integration together with international competition in education. To standardise new curricula and educational contents in the direction of 
streamlining and modernisation suitable to ages, qualifications and occupations, to attach importance to developing learners' qualities and capabilities (Tran, 2014a).

Fourthly, education and training, science and technology together with economic and social development are increasingly dialectical and effective. Higher education is transformed mainly from equipping knowledge to comprehensively developing the capacity and quality of learners, learning along with the practice, the theory is attached to the practice.

The fifth point is the general development mechanism of education, market and socio-economic is the increasingly compatible and correlated; improved and effective implementation of social welfare; characteristics, features, nature of service and service provision are on the rise.

The sixth point is forming a philosophy of the need for lifelong learning, strongly promoting socialisation, bringing together the state and the people in the development of higher education. Perfecting the higher education system towards open education and building a learning society.

And finally, the higher education quality assurance becomes a matter for the whole society, one of the many necessary and sufficient factors to expand international collaboration.

The important elements mentioned above are the prerequisites necessary for renovating and modernising the educational system. For education and pedagogy to be successful, the strategy for the development of higher education in Vietnam cannot be out of these characteristics.

When Vietnam's higher education is renovated under these conditions, the criteria have been experimentally planned to give some optimal features of higher education, namely:

- High quality and effective education;

- Unique educational method;

- $\quad$ Low cost, appropriate tuition fee;

- Suitable investment in infrastructure and facilities;

- Internship opportunities and attractive job placements.

These characteristics are necessary and sufficient conditions for Vietnam Education to integrate and cooperate fully with other advanced educational institutions in the world, including Asian higher education.

\section{Conclusion}

Bill Gates, the founder of Microsoft Corporation, asserts: "One of the most amazing things over the past 20 years has been the advent of the Internet. The Internet itself has made the world very small, the geographical distance has been flattened ... Another great thing is that more and more universities around the world are giving lectures online. You can be anywhere in the world to choose lectures, topics ..., even reputable professors to study without paying. This will be a radical change in the education system in the future."

Building a smart school and applying information technology (IT) based on Industry 4.0 is necessary, it becomes an obvious goal; thanks to IT, the world is brought together, the exchange of scientific fields is more convenient and efficient.

Besides systematic shortcomings like the quality of education, educational methods, etc, Vietnam's higher education has asserted itself in the revival period; new arguments, scientific arguments and the application of Industry 4.0 in the right frame of education to be a leverage to develop education; to educate the educator, educate the human life.

In short, the realities, achievements, challenges, opportunities and solutions have brought higher education to a new level, with rapid development and remarkable achievements, standing firmly on the path of comprehensive cooperation and international integration. 


\section{References}

Boyatzis, R.E. (1982): The Competent Manager, John Wiley and Sons, New York, NY.

Boyatzis, R.E., Cowen, S.S., Kolb, D.A. et al. (1995): Innovation in Professional Education: Steps on a Journey from Teaching to Learning, Jossey-Bass, San Francisco, CA.

Doan, T. M. T. (co-editor, 2012): Design and develop a training program that meets learning outcomes, Ho Chi Minh: Publisher of Vietnam National University.

Dooley, L. M., Paprock, K. E., Sun, I., \& Gonzalez, E. G. Y. (2001): Differences in priority for competencies trained between U.S. and Mexican trainers, Unpublished manuscript.

Kerka, S. (20o1): Competency-based education and training. ERIC Clearinghouse on Adult, Career and Vocational Education, Columbus, OHIO. [On-line].

Le, K. B. (2012): Effective college education, Publisher of Pedagogical University.

McLagan, P. A. (1996): Great ideas revisited. Training and Development, 50 (1), 6o-66.

Nguyen, C. K. and Dao, T. O. (2015): Textbook for test, assessment in education, Publisher of Pedagogical University.

Nguyen, H. L. (2014): Integrated training program: from design to operation, Ho Chi Minh: Publisher University of Education HCMC.

Nguyen, H. L. (2003): Role and competency profiles of human resource development practitioners in Vietnam, SwissAIT-Vietnam, Hanoi: International Conference on Management Education for 21st Century Proceedings.

Paprock, K. E. (1996): Conceptual structure to develop adaptive competencies in professional. IPN Ciencia, Arte: Cultura, Nueva Epoca, 2 (8), 22-25.

Rausch, E., Sherman, H., and Washbush, J. B. (2001): Defining and assessing competencies for competency-based, outcome focused management development, Journal of Management Development, Vol. 3, 184-200.

Tran, K. D. (2014a): Education and human resources development in the 21st century, Vietnam: Vietnam Education Publishing House.

Tran, K. D. (2014b): Theories and methods of modern teaching, Hanoi: Ha Noi National University Publisher.

Tran, K. D. (2015): Capacity and Creative Thinking in Higher Education, Hanoi: Hanoi National University Publisher. 